\title{
Pharmacist Role in Pharmaceutical Care during Ramadan
}

\author{
Osama H. Mohamed Ibrahim ${ }^{1,2}$ \\ ${ }^{1}$ Department of Clinical Pharmacy, College of Pharmacy, Cairo University, Cairo, Egypt \\ ${ }^{2}$ Departments of Pharmacy Practice and Pharmacotherapeutics, College of Pharmacy, University of Sharjah, \\ Sharjah, UAE \\ Email: oibrahim@sharjah.ac.ae
}

Received 27 November 2015; accepted 27 December 2015; published 30 December 2015

Copyright (C 2015 by author and Scientific Research Publishing Inc.

This work is licensed under the Creative Commons Attribution International License (CC BY). http://creativecommons.org/licenses/by/4.0/

(c) (i) Open Access

\section{Abstract}

Introduction: Ramadan is the ninth month in the Islamic Hijri calendar where Muslims are expected to fast every day from dawn to sunset. The eating behavior changes during Ramadan and the abstinence of food affects the oral drugs administration and other convenience dosage forms. There is a need to highlight and illustrate the role of the pharmacists in medication adjustment challenges that the patients conquer in the Holy month of Ramadan. Objectives: To estimate the awareness of pharmacists' role in providing pharmaceutical care during Ramadan; moreover, to explore pharmacists' perspective on the importance of medication regimen adjustment along with the proper counseling required to optimize patients' health throughout fasting. Method: This is an observational study that was done through dissemination of a cross-sectional survey among 130 pharmacists covering Abu Dhabi, Dubai, Sharjah, Ajman, and Northern Emirates regions. The targeted population consisted of practicing community pharmacists and hospital pharmacists across UAE. Results: Among pharmacists participated in the study 115 pharmacists $(88.5 \%)$ were Muslims and 79 pharmacists $(60.8 \%)$ were Arabs. 126 pharmacists $(97 \%)$ reported performing one or more kinds of medication regimen adjustment around Ramadan for at least one patient. Changing the frequency had the highest percentage by the pharmacist compared to other methods of regimen adjustment (39\%). Moreover, the results revealed that $46.9 \%$ of the pharmacists chose not to change the medication itself. Nineteen percent of Muslim pharmacists initiated the conversation about medication regimen adjustment $(P=0.0448)$ compared to non-Muslims, while14\% of pharmacists were Arabs who showed no statistically significant difference. Conclusion: In conclusion, pharmacists are more qualified to adjust and manage medication regimens than what they are presently performing. Utilization of such skill is required to adjust patients' medication regimen during fasting the Holy month of Ramadan and to ensure safe transition for fasting patients into and out of Ramadan. 


\section{Keywords}

\section{Pharmaceutical Care, Ramadan, Role of Pharmacists, Dose Regimen}

\section{Introduction}

Patients with acute and chronic conditions confront cognitive, practical, motivational and social obstacles during fasting in Ramadan. Few researches have investigated how approximately 14 hours fasting may affect or challenge patient's adherence to their medications. There is a need to highlight and illustrate the role of the pharmacists in medication adjustment challenges that the patients conquer in the Holy month of Ramadan. The eating behavior changes during Ramadan and the abstinence of food from dawn to sunset in which the oral drugs administered and other convenience dosage form are shifted from day to night. Thus, this change may be related to non-compliance or discontinuation that may proceed afterward and have poor health outcomes with increased recurrences and/or shortened survival [1].

In the Islamic Hijri calendar there is a month that Muslims refrain from food and drinks for a particular period of the day. However, after sunset to dawn, food is allowed as pre-fast meal (Sohour) before dawn and as post fast meal (Iftar) after sunset [1]-[3]. Although it is stated in Islam that ill people are exempted from the obligation of fasting many patients insist to take the risk by stopping, changing, reducing, medication doses or intervals regardless of medical advice [4]. According to a study by Aslam M, et al. [5] done in Saudi Arabia, 45.7\% of patients changed timing of their medication while $43.2 \%$ missed their scheduled doses; $9.8 \%$ administered their medication at different time and $4.4 \%$ took the medication as one single dose after Iftar meal. In addition, another study conducted in a Kuwaiti Hospital showed that the majority of patients changed their drug regimen during Ramadan; $60 \%$ and $18 \%$ patients took therapeutically scheduled change, and administered their medication either before Sohour or right after Iftar as a single intake. This abrupt adjustment in the medications has hazardous consequences in patient's health [5].

The fasting duration daily starts from dawn and continues until dusk; afterwards the patients break their fast at sunset with an evening meal (Iftar). In a diabetic patient this may precipitate hypoglycemia during the day. Furthermore, at sunset/dusk the patient traditionally consumes high sugar content meal, which can lead to hyperglycemia [6]. Based on a hospital study of 334 patients conducted during Ramadan of 2006 in Oman, 93.1\% of type 2 diabetic patients fasted the whole month. As a result $83.2 \%$ of these patients had uncontrolled fasting blood sugar levels. Besides that, the doses of $49.5 \%$ of diabetic patients taking Insulin/Oral Anti Diabetic Drug were unchanged [5] [7]-[9].

Two variant sorts of measurements timetable are regularly utilized throughout Ramadan, 1) Single daily dose and 2) Two or more daily doses. The simplest circumstance is that patients have a customary single evening dose. Their therapeutic scheme stays unaltered throughout Ramadan, as it is not affected by fasting. A comparative study of the pharmacokinetics of theophylline before and throughout Ramadan in healthy volunteers demonstrated a paramount decrease in the amount of the drug absorbed for the 8 pm consumption (around 2 hours after Iftar) compared with the 4 am consumption (immediately after Sohour) [10]. This effect was mostly illustrated by the progression in the circadian varieties of the gastric $\mathrm{pH}$ and by the modification of rhythms and quality of meals during Ramadan [11].

In general drug food interactions can systemically lead to reduced, delayed or increased drug availability in the body. In the month of Ramadan, the eating behavior, pattern and contents of meal are extremely modified which have a superior effect on the degree of food interactions [12]-[16].

A number of epidemiological studies aimed to ascertain whether there was a difference in the number of Muslims entering to the emergency room during the month of Ramadan and the rest of the year. Their outcomes indicated a fundamentally increase in the number of Emergency room visit frequencies for hypertension and migraine attacks in Ramadan compared to the rest of the year. Beside that another study demonstrated a rise in the number of cases with renal colic throughout the initial two weeks of Ramadan [17] [18].

The aim of establishing this study was to estimate the awareness of pharmacists' role in providing pharmaceutical care during Ramadan; furthermore, to explore pharmacists' perspective on the importance of medication regimen adjustment along with the proper counseling required to optimize patients' health during Ramadan. 


\section{Methodology}

This is an observational study that was done through dissemination of a cross-sectional survey among 150 pharmacists covering Abu Dhabi, Dubai, Sharjah, Ajman, and Northern Emirates regions. The targeted population consisted of practicing community pharmacists and hospital pharmacists across UAE. The period of the study was from January 2014 till July 2014. The response was 130 out of 150 targeted participants. The planned targets of population were 150 pharmacists and the total obtained was 130 , which give a response rate of $86.7 \%$.

Data were collected through a manual disseminated survey. Three data collectors visited different pharmacies, enrolled pharmacists, delivered and retrieved the survey forms. Because the study survey did not pose any risk for the participants and has no confidential data, it did not require the approval of University of Sharjah ethical committee but all the pharmacists singed an informed consent form before participating in the study. The questionnaire was validated by 12 randomly chosen pharmacists of the sampling set up. The respondent's comments and feedback on the application and clarity of items were considered in writing the final form of the survey. The confidentiality was maintained and pharmacists' information was kept anonymous. A self-administered 28 items survey was constructed to estimate the awareness of pharmacists in medication regimen adjustment during Ramadan. The survey contained close-ended questions. During distribution of the surveys the conductors emphasized that a pharmacist implemented a change the physician has made is not considered as a medication regimen adjustment done by the pharmacist. The first part of the survey involved questions about the demographics data of the pharmacists such as gender, age, current education level, religious affiliation, ethnicity, years of work experience and location of the pharmacy were considered. The second part involved questions about what proportion has the pharmacists suggested a change in medication regimen to the patients including changing in frequency, decreasing or increasing the dose, changing the medication dosage form to a different dosage form and changing the medication to a different medication. In addition, the third part of the survey included questions regarding the proportion of patients asking a pharmacist rather than a physician to adjust their medications and the capability of the pharmacist to adjust the medication regimen. Moreover, they were asked about their opinion if the physician or the pharmacist should make the decision of adjusting the medications. Then the pharmacists were questioned about their opinion on what proportion of patients need a pharmacist to adjust their medication regimen and what proportion will benefit from these adjustments.

The data then were analyzed statistically using Statistical Package for Social Sciences (SPSS) program Version 20 (Chicago, USA) statistical calculator program to perform descriptive statistics and to determine if there is any significant difference between groups when demographic date were taken in consideration. A P-value of $<0.05$ was considered as a cutoff point for statistical significance.

\section{Results}

\subsection{Sample Demographics}

Pharmacists' demographics with descriptive statistics are displayed in Table 1 . The results show that $88.5 \%$ of the pharmacists were Muslims and most of the ethnicities were Arabs (60.8\%). Male gender had a higher percentage (56.2\%). The range of age that dominated was 30 - 49 years old with an average age of 44 years old. Majority of the respondents (82.3\%) hold a bachelor degree in Pharmacy.

The remaining (17.7\%) hold a Pharm Ddegree. The results revealed that $46.2 \%$ of the pharmacists in this study have experience ranged from 0 - 5 years.

\subsection{Pharmacists' Implementation Questions}

The descriptive analysis on the change implemented by the pharmacists in the medication regimen is mentioned in Figure 1.

Of the total sample, 97.7\% pharmacists reported performing one or more kinds of medication regimen adjustment around Ramadan for at least one patient. Changing the frequency had the highest percentage by the pharmacists compared to other methods of regimen adjustment (38.5\%). Moreover, the results revealed that $46.9 \%$ of the pharmacists chose not to change the medication itself.

Forty two percent of the patients asked the pharmacists rather than the physicians to adjust their medication regimens. 


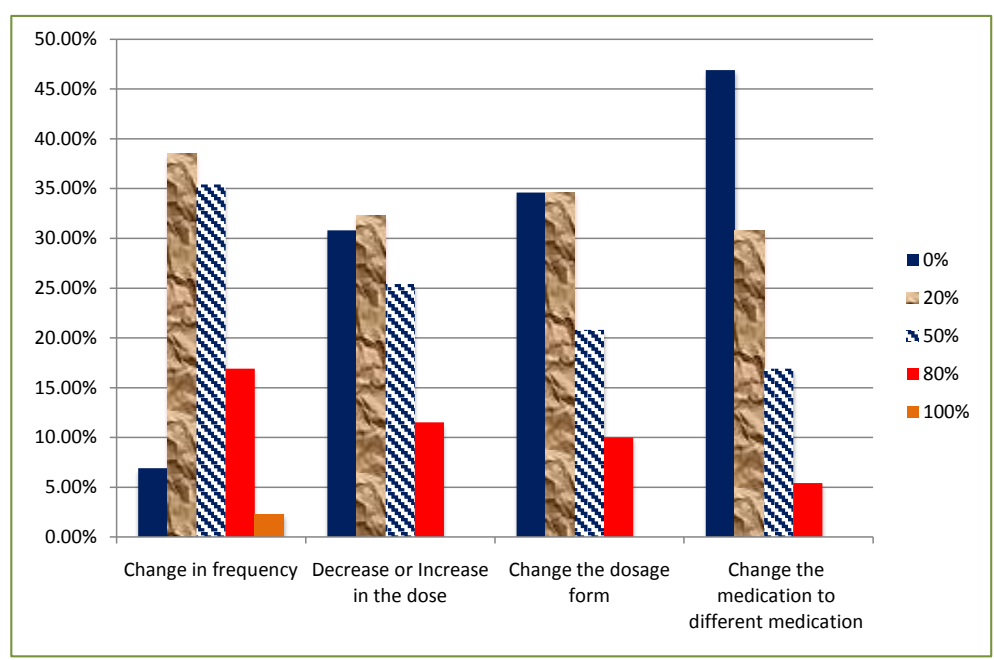

Figure 1. The change implemented by the pharmacists in the medication regimen.

Table 1. Pharmacist demographics.

\begin{tabular}{|c|c|}
\hline Pharmacist characteristics & $\%$ \\
\hline \multicolumn{2}{|c|}{ Gender $(n=130)$} \\
\hline Male & $73(56.2 \%)$ \\
\hline Female & 57 (43.8\%) \\
\hline \multicolumn{2}{|c|}{ Age $(n=130)$} \\
\hline Range & 23 - 65 years \\
\hline Mean & 44 years old \\
\hline \multicolumn{2}{|c|}{ Religion } \\
\hline Muslim & 115 (88.5\%) \\
\hline Non-Muslim & $15(11.5 \%)$ \\
\hline \multicolumn{2}{|c|}{ Ethnicity } \\
\hline Arab & $79(60.8 \%)$ \\
\hline Non-Arab & $51(39.2 \%)$ \\
\hline \multicolumn{2}{|c|}{ Location of the pharmacy in UAE } \\
\hline Abu-Dhabi (including its suburbs) & $59(45.5 \%)$ \\
\hline Dubai & $15(11.5 \%)$ \\
\hline Sharjah & $19(14.6 \%)$ \\
\hline Ajman & $26(20 \%)$ \\
\hline Northern Emirates & $11(8.5 \%)$ \\
\hline \multicolumn{2}{|c|}{ Years of experience } \\
\hline 0 - 5 years & $60(46.2 \%)$ \\
\hline 6 - 11 years & 38 (29.2\%) \\
\hline 11 - 15 years & $22(17 \%)$ \\
\hline 16 - 20 years & $5(3.8 \%)$ \\
\hline Above 20 years & $5(3.8 \%)$ \\
\hline
\end{tabular}


Pharmacists' confidence in their capability to change the medication schedule regardless the type of alteration to fit patients' fasting during Ramadan was evaluated. Only 6\% of pharmacists reported that they are extremely capable to alter medication regimen, $42 \%$ pharmacists reported to be capable, and $29 \%$ of pharmacists reported to be somewhat capable. On the other hand, $19 \%$ of pharmacists reported to be slightly capable and $4 \%$ reported no capability.

Figure 2 demonstrates the pharmacists' opinion in the proportion of the patients that need a pharmacist intervention to adjust their medication regimens during Ramadan. The majority of the pharmacists (44.6\%) reported that $50 \%$ of patients need pharmacist intervention to adjust their medications during Ramadan.

Regarding the proportion of patients that would benefit from pharmacist intervention to adjust their medication regimen during Ramadan, results indicated that the majority of the pharmacists (99.2\%) agreed on that patients would benefit from the pharmacists intervention. While only $0.8 \%$ of pharmacists believed that there is no benefit of the pharmacist involvement in the medication regimen adjustment. Furthermore, the percentage of pharmacists believed that all the patients would benefit from pharmacist intervention during Ramadan were $6.8 \%$.

Thirty eight percent of pharmacists found adequate time to counsel the patients during Ramadan. Some pharmacists' found that the time to counsel the patients during Ramadan was somewhat adequate (29\%) while others thought time for counseling was extremely adequate (8\%). Slight adequacy was stated by $25 \%$ pharmacists. None of them reported inadequacy of time.

About one third (31\%) of pharmacists expressed their workload at the pharmacy during Ramadan to be somewhat high while $11 \%$ of pharmacists claimed that they had extremely high workload during Ramadan.

A five point Likert scale was used to assess pharmacists' level of confidence in their scientific and therapeutic knowledge in adjusting medication regimen during Ramadan. The results in Figure 3 showed that $41 \%$ of pharmacists were confident but $2 \%$ were not confident at all. The rest of the data is available in the figure.

Pharmacists were asked about how important medication regimen adjustment would be on the pharmacy revenue using a question of a five-point scale ranging from not important at all to extremely important. The results showed that $35 \%$ of the pharmacists believed that it would be motivating if this activity will increase the pharmacy revenue. A question about the most common diseases that required medication adjustments during the month of Ramadan was included in the survey. Each pharmacist listed the most common diseases that he/she had helped patients to adjust their regimens during Ramadan. In total a list of 28 diseases was recorded by 130 pharmacists and the Figure 4 shows the most frequent diseases mentioned by the pharmacists.

Pharmacists were inquired about their opinion if the physician or the pharmacist should make the decision of adjusting the medications. Half of the pharmacists agreed on the physician as decision maker for medication adjustment, while $29.3 \%$ agreed on pharmacist as the decision maker and $20 \%$ stated that both physician and pharmacists should be decision makers.

Regarding the question about who begins the conversation about the medications adjustment with patients, results of this question showed that majority of the pharmacists wait for the patients in most cases to ask for the adjustment. On the other hand, $21.6 \%$ of the pharmacists took action to start the conversation.

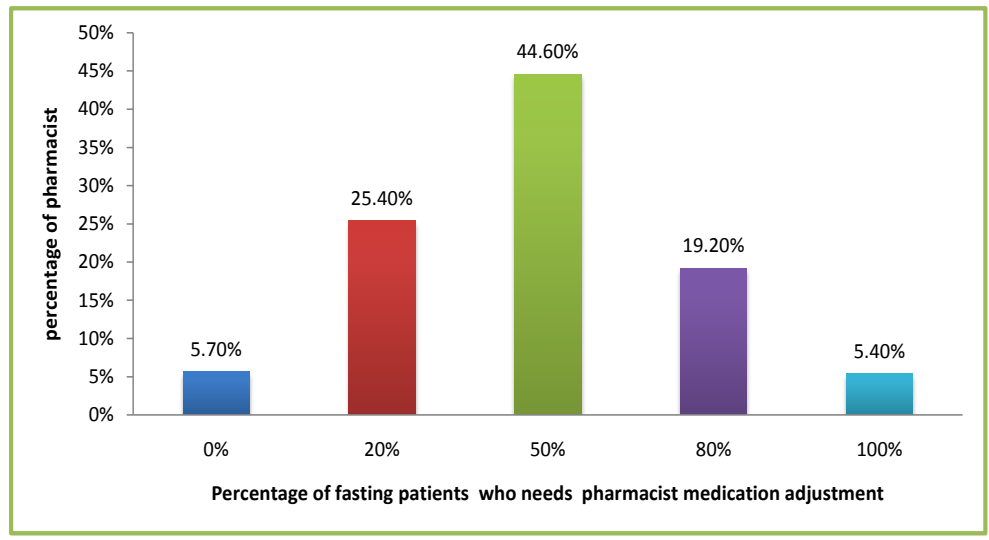

Figure 2. Pharmacists' response to the question "In your opinion what proportion of patients need a pharmacist to adjust their medication regimens during Ramadan?”. 


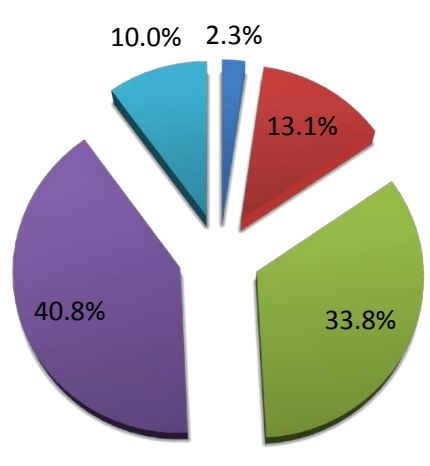

not confident at all

alightly confident

- somewhat confident

confident

- extremely confident

Figure 3. Pharmacist confidence regarding medication adjustments.

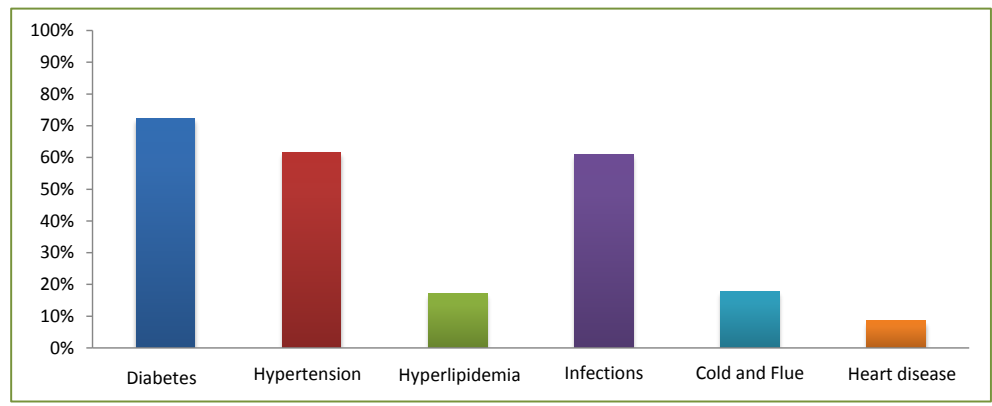

Figure 4. Diseases that require medication adjustment during the month of Ramadan.

Table 2 \& Table 3 show the comparison between the initiation of conversation about regimen adjustment in association with ethnicity or religious affiliation.

The religious affiliation showed statistical significance difference as higher percentage of Muslim pharmacists initiated the conversation about medication regimen adjustment during Ramadan compared to Non-Muslim pharmacists (P value $<0.05$ ).

On the other hand, ethnicity showed no statistically significant different in initiating the conversation about medication regimen adjustment during Ramadan. Thirty three percent of the pharmacists started the conversation about medication adjustment with patients having chronic disease on the first week of the last Ramadan. Moreover 29\% initiated the conversation 1 - 3 days before Ramadan. Thirteen percent of the pharmacists had the conversation at least seven days before Ramadan.

More pharmacists intervened with patients coming with acute condition during the month of Ramadan (40.8\%) while $19.2 \%$ stated that they intervened more in chronic conditions and $34.6 \%$ reported an equal rate of involvement in acute and chronic conditions Figure 5.

A question in the survey was written to inspect if there are any provided guidelines from the health authority emphasizing on patients' medication adjustments during the month of Ramadan. The results revealed that almost two third of the pharmacists stated that there were no guidelines for medication adjustment during Ramadan. A comparison between the availability of the guidelines with the demographics of the respondents who stated "YES" to the presence of the guidelines showed that Abu-Dhabi has the highest number of pharmacists confirmed the availability of the guidelines. Also higher percentage of pharmacists with less experience (less than 10 years) admitted the existence of medication adjustment protocols during Ramadan compared with pharmacists with more experience (more than 10 years). In both cases the difference was statistically significant difference with P-value $<0.05$.

Regarding the association of pharmacist role in adjusting medication regimens with the years of work experience, $74 \%$ of pharmacists with less than 10 years of experience had pointed out that the pharmacist is the one 


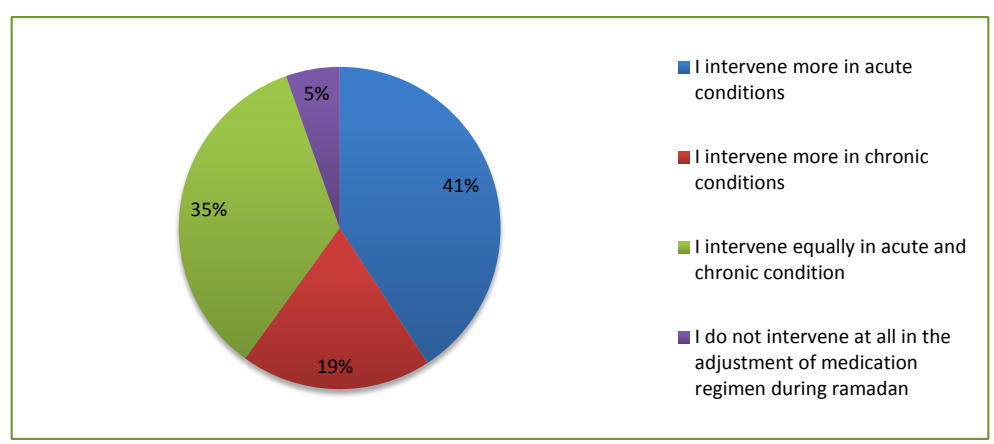

Figure 5. Involvement in the medication regimen for patients with chronic conditions compared to acute conditions.

Table 2. Initiation of conversation about adjusting medication regimen related to ethnicity.

\begin{tabular}{cccc}
\hline & Arab & Non-Arab & Total \\
\hline The patient in all cases & $10(7.7 \%)$ & $11(8.5 \%)$ & $21(16.2 \%)$ \\
The patient in most cases and I do in a few cases & $31(23.8 \%)$ & $23(17.7 \%)$ & $54(41.5 \%)$ \\
The patient in about half of the cases and I do in the other half & $20(15.4 \%)$ & $7(5.4 \%)$ & $27(20.8 \%)$ \\
I start in most cases and the patient in a few case & $17(13.1 \%)$ & $7(5.4 \%)$ & $24(18.5 \%)$ \\
I start in all cases & $1(0.77 \%)$ & $3(2.31 \%)$ & $4(3.1 \%)$ \\
Total & $79(60.8 \%)$ & $51(39.2 \%)$ & 130 \\
\hline
\end{tabular}

Table 3. Initiation of conversation about adjusting medication regimen related to religious affiliation.

\begin{tabular}{cccc}
\hline & Muslim & Non-Muslim & Total \\
\hline The patient in all cases & 19 & $2(1.54 \%)$ & $21(16.2 \%)$ \\
The patient in most cases and I do in a few cases & $48(36.9 \%)$ & $6(2.62 \%)$ & $54(41.4 \%)$ \\
The patient in about half of the cases and I do in the other half & $23(17.7 \%)$ & $4(3.08 \%)$ & $27(20.7 \%)$ \\
I start in most cases and the patient in a few cases & $21(16.25 \%)$ & $3(2.31 \%)$ & $24(18.5 \%)$ \\
I start in all cases & $4(3.1 \%)$ & 0 & $4(3.1 \%)$ \\
Total & $115(88.5 \%)$ & $15(11.5 \%)$ & 130 \\
\hline
\end{tabular}

responsible in adjusting medications during Ramadan while only (26\%) of the pharmacists with experience of more than 10 years agreed on this. The results showed a statistically significant difference with a $\mathrm{P}$ value $<0.05$.

\section{Discussion}

The current study focused on the behavior of the pharmacists and their perception in implementing changes in medication regimens for the fasting patients. Throughout the study pharmacists were being able to perform medication regimen adjustment that revealed that they might be more open to greater role than the one they are presently performing. Some of the questions in the current survey were adopted from a similar study was done by Amin et al. in Egypt [1]. The results of this study were a little bit different from the results of the Egyptian study especially in the aspect of the impact of religion of the pharmacists and their enthusiasm to adjust the medication regimen for their patients in Ramadan as will be discussed in the following paragraphs.

Pharmacists reported that the most common approaches to adjust the medication regimen during Ramadan is by changing the frequency of taking the medications. Changing the frequency of medication turned out to be simpler thus more practical for patients making their fasting easier therefore, enhancing their compliance. On the 
other hand, changing the medication itself to a different medication of the same therapeutic class or a totally different class was the least option chosen by the pharmacists. This is because of the fact that the pharmacists have limited access to patients' medical record to make such adjustment hence they do not have the right to change the medication without the physician's consultation and approval.

As a result of pharmacists' accessibility, availability of the community pharmacies, being the drug expert and being the one who dispenses the medications with free of charge consultation, $42 \%$ of patients seek the pharmacists' opinion for medication adjustments rather than the physicians' opinion.

Pharmacists have a unique position that puts them in an environment where they serve as the main source of information. As a result, many patients see the pharmacists as a substitute for general practitioner. Accordingly, our study shows that $44.6 \%$ of patients need a pharmacist to adjust their therapy. In some cases fasting patients may adjust their medication regimens on their own and then they come to the pharmacist with a resulting health problem [19]. This highlighted the need and the benefit of pharmacist intervention to the adjustment in medication regimen as indicated in our study by (99.2\%) of the pharmacists confirm the benefit of the patients from the pharmacists' information and experience in the modification of their therapeutic regimen.

Pharmacists who had adequate time to counsel and those who initiate the conversation about medication regimen adjustment were more liable to perform therapeutic adjustment for their patients.

Regarding the initiation of the conversation about medication adjustment with patients, comparison was made to see if religion affiliation and/or ethnicity of the pharmacists had an effect on the medication therapy management. The religion affiliation of the pharmacist played an important factor in initiating the conversation which showed statistical significance of a $(\mathrm{P}$-value $=0.044)$ where majority of Muslim pharmacists initiate the conversation regarding the patients' medication adjustment. In contrary to Amin et al. the parameters religion, ethnicity, age and level of experience of the pharmacists weren't related to the medication adjustment. Yet it was associated with higher level of confidence of therapeutic information regarding the Medication regimen in Ramadan [1]. One survey in Qatar stated that Muslim pharmacists were aware of changing their patient's medication regimen specially the ones with chronic conditions because of their medical education and personal acumen [20]. Other studies showed that Muslim patients living in foreign countries such as in North America, Europe, and Australia had low rates of information regarding their general health or particular medication adjustment provided by health professionals in Ramadan [21]-[24].

In connection to Ramadan, pharmacists have a critical potential to guarantee the medical safety of their patients through an early intervention in medication regimen modification. In this study, 33\% of pharmacists started the conversation on the first week of last Ramadan. Meanwhile, $29 \%$ of the pharmacists initiated the conversation 1 - 3 days before Ramadan in which these results were similar to the Egyptian study [1]. According to Al-Arouj et al. diabetic patients should have an assessment one to two months prior to Ramadan [25].

It's more desirable by the pharmacists to initiate the conversation if they anticipated that the medication regimen adjustment would increase the pharmacy revenue. This was seen in the current study in almost $35 \%$ of the pharmacists. It is likely to estimate that this type of discussion could reinforce the pharmacist-patient relationship that will support the loyalty to the pharmacy resulting in increased profit. Previous research in developing countries also suggested that profit could be an important factor influencing pharmacists' behavior [26]. Apart from the study mentioned above, pharmacists as care givers and from the seven-star definition of pharmacists by the WHO, the pharmacist concern should be patient oriented towards better health outcomes regardless the profitability [27].

Around twenty nine percent of the respondents confirmed the existence of guidelines provided by health authorities emphasizing on patients' medication adjustment during Ramadan. Further interpretation was done to assess if awareness about the availability of the guidelines was affected by gender, location and years of experience of the pharmacists. The results showed no statistically significant difference in relation to the gender. Nevertheless, results based on the location showed statistical significance $(P<0.05)$ where Abu Dhabi scored highest among the UAE region. This is because of the presence of awareness campaigns held by Abu Dhabi Health Authority to the public that were published in newspaper. One more statistical significant difference revealed in our study was based on the years of work experience $(P$-value $=0.04)$ that indicated pharmacists with less years of experience claimed the presence of the guidelines. This might be due to the fact that they were freshly graduates, or had been exposed to updated information and were eager to look up for guidelines to improve their working experience.

Based on the question were pharmacists selected the common diseases that require medication adjustment during Ramadan. Diabetes earned the first place between all diseases (72.3\%) as UAE is ranked 15th worldwide, 
with $18.98 \%$ of the UAE population living with diabetes [28]. A study by Wilbur et al. was conducted prior to Ramadan in July 2012. This study was carried out in Qatar, intended to describe pharmacists' practice, information, and behavior towards better medication adjustment for patients with diabetes during Ramadan. The result revealed that very few pharmacists reported never interacting with diabetes patients [20]. Despite the fact that diabetes management is crucial during Ramadan, not all pharmacists know how to implement the proper management in diabetes medication.

Another aspect discussed in this survey was the pharmacists' perception on their role in medication adjustment in fasting patients. Half of the pharmacists agreed on the physician as a decision maker in regimen adjustment, while the rest agreed on pharmacists in $30 \%$ and both as decision maker in $20 \%$. The job of drug experts has advanced from traditional dispensing to delivering complete medication therapy management as a team with other health care providers. According to the 2009 National Pharmacist Workforce Survey, pharmacists are investing less time in dispensing and more time providing direct patient care and education [29]. For example a study was done to inspect whether interference by a clinical pharmacist would have an impact on adherence to antiretroviral (ARV) agents in HIV positive patients. The pharmacist was able to apply the use of combined medications, which reduces the interactions and adverse effects through avoiding ARVs that need separate dosing [30].

Regarding the comparison were pharmacists take the responsibility to adjust medication regimen based on the years of work experience. The results showed that pharmacists with less than 10 years of experience had higher votes in taking the responsibility in adjusting medications. This may be due to the fact that pharmacists with less experience are considered to be freshly graduated and were exposed to a more improved educational system than the pharmacists with more years of experience.

When the light spotted on the involvement of the pharmacists in medication regimen for patients with chronic conditions compared to patients with acute conditions it appeared that our results were identical with Amin et al. study about the matter. In this prior study, pharmacists were more inclined to interfere in patient's condition that were simple and steady such as acute respiratory illnesses rather than complex and chronic cases. Moreover, the extreme and sudden onset of acute conditions may make pharmacists feel ethically committed to start first aid measures before the patient visits a hospital [1].

\section{Limitations}

This study has some limitation that worth discussion. First of all, it is important to keep in mind that results of the study dependent upon the accuracy the respondents. Moreover pharmacists had to remember medication regimen adjustment commenced last Ramadan that act as a primary dependent factor in our research. Also, the sample size was relatively small to draw an inference for the whole pharmacists practicing in UAE taking in consideration that it was a convenient sample and not a random sample from the whole pharmacists practicing in UAE.

\section{Conclusion}

In conclusion, pharmacists are more qualified to adjust and manage medication regimens than what they are presently performing. Utilization of such skill is required to adjust patients' medication regimen during fasting the Holy month of Ramadan and to ensure safe transition for fasting patients into and out of Ramadan. It is essential for the pharmacists to begin the conversation about medication regimen adjustment with Muslim patients before Ramadan to recognize how they can help them to adjust their medication regimens while fasting.

\section{Conflict of Interest}

The author claims no conflict of interest.

\section{Acknowledgements}

The author would like to thank all the pharmacists who contributed to this study for their time and efforts.

\section{References}

[1] Amin, M.E. (2013) Pharmacists' Role in Adjusting Medication Regimens for Muslim Patients in Ramadan. ProQuest 
Dissertations and Theses, 168. http://search.proquest.com/docview/1438061372

[2] Zeeneldina, A., Gaber, A. and Taha, F. (2012) Does Fasting during Ramadan Trigger Non-Adherence to Oral Hormonal Therapy in Breast Cancer Patients? Journal of the Egyptian National Cancer Institute, 24, 133-137. http://dx.doi.org/10.1016/j.jnci.2012.06.003

[3] Chamsi-Pasha, H., Ahmed, W.H. and Al-Shaibi, K.F. (2014) The Cardiac Patient during Ramadan and Hajj. Journal of the Saudi Heart Association, 26, 212-215. http://dx.doi.org/10.1016/j.jsha.2014.04.002

[4] Aydin, O., Celik, G.E., Onen, Z.P., et al. (2012) How Do Patients with Asthma and COPD Behave during Fasting? Allergologia et Immunopathologia, 42, 115-119. http://dx.doi.org/10.1016/j.aller.2012.07.010

[5] Aslam, M., et al. (1997) Pharmacist, Medicines and the Fast of Ramadan. Pharmaceutical Journal, 259, 973-975.

[6] Akbani, M.F., Saleem, M., Gadit, W.U., Ahmed, M., Basit, A. and Malik, R.A. (2005) Fasting and Feasting Safely during Ramadan in the Patient with Diabetes. Practical Diabetes International, 22, 100-104. http://dx.doi.org/10.1002/pdi.767

[7] Ramadan Health Guide (2007) http://www.ramadan.co.uk/RamadhanHealth_Guide.pdf

[8] Jarrar, Y.B. (2011) Pharmaceutical Practice and Selling of Drugs during Ramadan. Libyan Journal of Medicine, 6, 5775. http://dx.doi.org/10.3402/ljm.v6i0.5775

[9] Aadil, N., Houti, I.E. and Moussamih, S. (2014) Drug Intake During Ramadan. BMJ, 329, 778-782. http://dx.doi.org/10.1136/bmj.329.7469.778

[10] Gay, J.P., Cherrah, Y., Aadil, N., Hassar, M., Brazier, J.L. and Ollagnier, M. (1990) Influence of Ramadan on the Pharmacokinetics of a SR Preparation of Theophylline and Cortisol Cycle. Journal of Interdisciplinary Cycle Research, 21, 190-192. http://dx.doi.org/10.1080/09291019009360052

[11] Iraki, L., Bogdan, A., Hakkou, F., Amrani, N., Abkari, A. and Touitou, Y. (1997) Ramadan Diet Restrictions Modify the Circadian Time Structure in Humans: A Study on Plasma Gastrin, Insulin, Glucose, and Calcium and on Gastric $\mathrm{pH}$. The Journal of Clinical Endocrinology \& Metabolism, 82, 1261-1273. http://dx.doi.org/10.1210/jc.82.4.1261

[12] Saour, J.N., Sick, J.O., Khan, M. and Mamo, I. (1989) Does Ramadan Fasting Complicate Anticoagulant Therapy? Annals of Saudi Medicine, 9, 538-540.

[13] Aslam, M. and Wilson, J.V. (1992) Medicines, Health and the Fast of Ramadan. The Journal of the Royal Society for the Promotion of Health, 112, 135-136. http://dx.doi.org/10.1177/146642409211200308

[14] Hamaguchi, T., Shinkuma, D., Irie, T., Yamanaka, Y., Morita, Y., Ivanoto, B., et al. (1993) Effect of High-Fat Meal on the Bioavailability of Phenytoin in a Commercial Powder with a Large Particle Size. International Journal of Clinical Pharmacology, Therapy and Toxicology, 31, 326-330.

[15] Wilder, B.J., Leppik, I., Hietpas, T.J., Cloyd, J.C., Randinitis, E.J. and Cook, J. (2001) Effect of Food on Absorption of Dilantin Kapseals and Mylan Extended-Release Phenytoin Sodium Capsules. Neurology, 57, 571-573. http://dx.doi.org/10.1212/WNL.57.4.582

[16] Erkekol, F.O., Celik, G.E., Keskin, O., Gullu, E., Mungan, D. and Misirligil, Z. (2006) Fasting: An Important Issue in Asthma Management Compliance. Annals of Allergy, Asthma \& Immunology, 97, 370-374. http://dx.doi.org/10.1016/S1081-1206(10)60803-4

[17] Topacoglu, H., Karcioglu, O., Yuruktumen, A., Kiran, S., Cimrin, A.H., Ozucelik, D.N. and Bozkurt, S. (2005) Impact of Ramadan on Demographics and Frequencies of Disease-Related Visits in the Emergency Department. International Journal of Clinical Practice, 59, 900-905. http://dx.doi.org/10.1111/j.1742-1241.2005.00460.x

[18] Abdolreza, N., Omalbanin, A., Mahdieh, T.S., Mohammad Ali, M.R., Reza, M.S., Maryam, S. and Mohsen, N. (2011) Comparison of the Number of Patients Admitted with Renal Colic during Various Stages. Saudi Journal of Kidney Diseases and Transplantation, 22, 1199-202.

[19] Barncard, C. (2013) With a Few Questions, Pharmacists Can Make Ramadan’s Fast Safe for Muslim Patients. http://www.news.wisc.edu/21955

[20] Wilbur, K., Al-Tawengi, K. and Remoden, E. (2014) Diabetes Patient Management by Pharmacists during Ramadan. BMC Health Services Research, 14, 117. http://dx.doi.org/10.1186/1472-6963-14-117

[21] Gaborit, B., Dutour, O., Ronsin, O., Atlan, C., Damon, P., Gharsalli, R., Pradel, V., Dadoun, F. and Dutour, A. (2011) Ramadan Fasting with Diabetes: An Interview Study of Inpatients' and General Practitioners' Attitudes in the South of France. Diabetes \& Metabolism, 37, 395-402. http://dx.doi.org/10.1016/j.diabet.2010.12.010

[22] Peeters, B., Mehuys, E., van Tongelen, I., van Bever, E., Bultereys, L., Avonts, D., Yildiz, G., Remon, J.P. and Boussery, K. (2012) Ramadan Fasting and Diabetes: An Observational Study among Turkish Migrants in Belgium. Primary Care Diabetes, 6, 293-296. http://dx.doi.org/10.1016/j.pcd.2012.02.003

[23] Pathy, R., Mills, K.E., Gazeley, S., Ridgley, A. and Kiran, T. (2011) Health Is a Spiritual Thing: Perspectives of Health 
Care Professionals and Female Somali and Bangladeshi Women on the Health Impacts of Fasting during Ramadan. Ethnicity \& Health, 16, 43-56. http://dx.doi.org/10.1080/13557858.2010.523780

[24] Peterson, S., Nayda, R.J. and Hill, P. (2012) Muslim Person’s Experiences of Diabetes during Ramadan: Information for Health Professionals. Contemporary Nurse, 41, 41-47. http://dx.doi.org/10.5172/conu.2012.41.1.41

[25] Al-Arouj, M., Assaad-Khalil, S., Buse, J., Fahdil, I., Fahmy, M., Hafez, S. and Thomas, A. (2010) Recommendations for Management of Diabetes during Ramadan. Diabetes Care, 33, 1895-1902. http://dx.doi.org/10.2337/dc10-0896

[26] Amin, M.E. and Chewning, B.A. (2011) Pharmacists Dispensing Antibiotics without a Prescription: A Qualitative Pilot Study. Paper Presented at the American Public Health Association 139th Annual Meeting, Washington DC, 29 October-2 November 2011.

[27] The Role of the Pharmacist in the Health-Care System-Preparing the Future Pharmacist: Curricular Development, Report of a Third WHO Consultative Group on the Role of the Pharmacist, 1997. http://apps.who.int/medicinedocs/en/d/Js2214e/3.2.html

[28] United Arab Emirates vs World Prevalence of Diabetes. International Diabetes Federation. Retrieved 15 May 2014. http://www.idf.org/membership/mena/united-arab-emirates

[29] Doucette, W.R., Gaither, C.A., Kreling, D.H., Mott, D.A. and Schommer, J.C. (2010) Final Report of the 2009 National Sample Survey of the Pharmacist Workforce to Determine Contemporary Demographic and Practice Characteristics.

[30] Ma, A., Chen, D.M., Chau, F.M. and Saberi, P. (2010) Improving Adherence and Clinical Outcomes through an HIV Pharmacist's Interventions. AIDS Care, 22, 1189-1194. http://dx.doi.org/10.1080/09540121003668102 